\title{
Establishment and characterization of a docetaxel-resistant human prostate cancer cell line
}

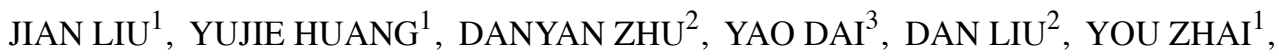 \\ XINGGUANG LIANG $^{4}$, LIHUA WU ${ }^{1}$ and QINGWEI ZHAO ${ }^{1}$
}

\begin{abstract}
${ }^{1}$ Research Center for Clinical Pharmacy, Zhejiang Provincial Key Laboratory for Drug Evaluation and Clinical Research, State Key Laboratory for Diagnosis and Treatment of Infectious Disease, The First Affiliated Hospital, Zhejiang University School of Medicine, Hangzhou, Zhejiang 310003; ${ }^{2}$ Institute of Pharmacology and Toxicology, Zhejiang University, Hangzhou, Zhejiang 310058, P.R. China; ${ }^{3}$ Department of Radiation Oncology, College of Medicine, University of Florida, Florida, FL 32610, USA; ${ }^{4}$ Key Laboratory of Clinical In Vitro Diagnostic Techniques of Zhejiang Province, The First Affiliated Hospital, Zhejiang University School of Medicine, Hangzhou, Zhejiang 310009, P.R. China
\end{abstract}

Received February 24, 2020; Accepted August 7, 2020

DOI: $10.3892 / 01.2020 .12093$

\begin{abstract}
The aim of the present study was to establish a novel docetaxel-resistant prostate cancer cell line and investigate its biological characteristics. The human prostate cell line, PC-3, was exposed to docetaxel, the concentrations of which were increased in a stepwise manner in the medium to select the drug-resistant cell line, PC-3/DTX. The morphological features were observed using inverted microscopy. The growth curves of PC-3 and PC-3/DTX cells were drawn to calculate the doubling time. Flow cytometry was performed to determine cell-cycle distribution. A 3-(4,5-dimethyl-2-thiazol)2,5-diphenyl-2H tetrazolium bromide assay was performed to
\end{abstract}

Correspondence to: Ms. Jian Liu or Ms. Qingwei Zhao, Research Center for Clinical Pharmacy, Zhejiang Provincial Key Laboratory for Drug Evaluation and Clinical Research, State Key Laboratory for Diagnosis and Treatment of Infectious Disease, The First Affiliated Hospital, Zhejiang University School of Medicine, 79 Qingchun Road, Hangzhou, Zhejiang 310003, P.R. China

E-mail: lindaliu87@zju.edu.cn

E-mail:qwzhao@zju.edu.cn

Abbreviations: PC-3/DTX, docetaxel-resistant PC-3 cells; mTOR, mammalian target of rapamycin; Akt, protein kinase B; p-AKT, phosphorylated Akt; ADT, androgen deprivation therapy; CRPC, castration-resistant prostate cancer; mCRPC, metastatic castration-resistant prostate cancer; CCK8, Cell Counting kit-8; $\mathrm{PI}$, propidium iodide; OD, optical density; $\mathrm{IC}_{50}, 50 \%$ inhibitory concentration; Td, growth curves and doubling time; PTEN, phosphatase and tensin homolog; mTORC1, mTOR complex 1; mTORC2, mTOR complex 2; PI3K, phosphoinositide 3-kinase; p70 S6K1, p70 S6 kinase 1; 4E-BP1, eukaryotic initiation factor 4E binding protein 1

Key words: prostate cancer, docetaxel, drug resistance, mTOR, PC-3/DTX test the drug resistance of PC-3 and PC-3/DTX cells. Western blot analysis was conducted to determine the protein expression levels of the mammalian target of rapamycin (mTOR) signaling pathway, which may serve a role in regulating drug resistance in the two cell lines. PC-3/DTX cells exhibited changes in morphology, proliferation rate, doubling time and cell-cycle distributions, compared with PC-3 cells. PC-3/DTX cells were 10.9-fold resistant to docetaxel in comparison with PC-3 cells. The results showed that PC-3/DTX cells overexpressed Rictor and p-AKT(S473) proteins, which are specific subunits or downstream substrates of mTORC2. The new findings suggested that the mTORC2 signaling pathway may serve an important role in the regulation of docetaxel drug resistance of PC-3 cells. In conclusion, PC-3/DTX cells may be applied to study the resistance of anticancer drugs and to identify methods to overcome resistance.

\section{Introduction}

The estimated number of new prostate cancer cases was $\sim 1.3$ million with 359,000 associated deaths worldwide in 2018 , with prostate cancer ranking as the second most common cancer and the fifth leading cause of cancer-associated mortality in males (1). Although it is highly curable if the tumor is locally confined, patients with advanced late-stage disease have a much lower 5-year survival rate ( 30\%) (2). Androgen deprivation therapy (ADT) is the standard-of-care for patients with advanced prostate cancer. Although highly effective initially, tumors eventually progress and transform themselves into castration-resistant prostate cancer (CRPC) (3). Metastatic CRPC (mCRPC) remains the main clinical challenge and a major cause of mortality (4). In patients with mCRPC, docetaxel currently serves as the standard first-line chemotherapy. However, in addition to its long-term toxicity, the benefits of docetaxel are generally restricted, and drug resistance occurs inevitably in nearly all patients. Clinical data have demonstrated that, in addition to the $\sim 50 \%$ of patients who fail to respond to docetaxel inherently, in most patients 
who initially respond to the drug, disease progression will recur within 1 year from the start of treatment, indicating the generation of acquired chemoresistance (5).

In this regard, docetaxel resistance has become a major clinical issue to overcome. Although extensive research has been performed into docetaxel resistance, there is no mechanism to explain in detail the clinical response to docetaxel therapy. Mammalian target of rapamycin (mTOR) is an oncoprotein that is generally dysregulated in human cancer (6). In prostate cancer, the mTOR pathway is frequently hyperactivated (7). The pivotal role of mTOR in prostate cancer makes it a potential target for therapeutic interventions.

To completely understand drug resistance, cultured cell lines resistant to anticancer drugs need to be primarily established. In the present study, a docetaxel-resistant prostate cancer cell line was established and the characteristics of docetaxel resistance in this cell line were examined. Furthermore, the mTOR signaling components were compared between the parental cells and cells that developed resistance to docetaxel to analyze the impact of mTOR signaling on the acquired docetaxel-resistant phenotype in preclinical CRPC models.

\section{Materials and methods}

Anticancer agents. Docetaxel (Sanofi S.A.) was dissolved in $95 \%$ ethanol to the stock concentration of $100 \mathrm{~nm}$ and stored at $4^{\circ} \mathrm{C}$.

Drug-resistant cancer cell lines. Docetaxel-resistant clones of PC-3 cells were developed by exposing cells to docetaxel at an intermittently increasing concentration. In brief, PC-3 cells were seeded onto a 96-well plate and exposed to $0.1 \mathrm{nM}$ docetaxel for $24 \mathrm{~h}$. Next, the medium was changed to normal culture medium (F-12 medium with $10 \%$ fetal bovine serum), and $100 \mathrm{U} / \mathrm{ml}$ penicillin and streptomycin (all purchased from (Thermo Fisher Scientific, Inc.). Following the PC-3 cells being cultured three times, the cells were continuously incubated with a higher concentration of $0.2 \mathrm{nM}$ docetaxel for $24 \mathrm{~h}$, prior to the medium being changed to normal cultured medium. This step was repeated with $0.50,0.75,1.00,1.50$, 2.00, 5.00, 7.50, 10.00, 15.00, 20.00 and $30.00 \mathrm{nM}$ docetaxel. $\mathrm{PC}-3$ cells that were resistant to $30 \mathrm{nM}$ docetaxel were named PC-3/DTX cells and stored for further investigation.

Cell culture. The human prostate cancer PC-3 cell line was purchased from American Type Culture Collection, Manassas, VA, USA (CRL-1435). In brief, PC-3 cells and docetaxel-resistance PC-3 cells (PC-3/DTX) were cultured in F-12 medium (Thermo Fisher Scientific, Inc.), supplemented with $10 \%$ fetal bovine serum (Thermo Fisher Scientific, Inc.), penicillin (100 U/ml; Thermo Fisher Scientific, Inc.) and streptomycin (100 U/ml; Thermo Fisher Scientific, Inc.). The cultures were maintained at $37^{\circ} \mathrm{C}$ in a $95 \%$ humidified atmosphere with $5 \% \mathrm{CO}_{2}$.

Growth curves of PC-3 and PC-3/DTX cells detected by CCK 8 assay. Cell proliferation were measured by Cell Counting Kit-8 (CCK-8; cat. no. C0037, Beyotime Institute of Biotechnology). To compare the viability of PC-3 and PC-3/DTX cells, cells were seeded onto 96-wells plates at a density of $2.0 \times 10^{3}$ cells/well. After $24 \mathrm{~h}$ incubation at $37^{\circ} \mathrm{C}$ in a $95 \%$ humidified atmosphere with $5 \% \mathrm{CO}_{2}, 10 \mu \mathrm{l} \mathrm{CCK8}$ solution was added into each well, and incubated at $37^{\circ} \mathrm{C}$ for $1 \mathrm{~h}$. Next, the absorption at $450 \mathrm{~nm}$ was measured using a microplate spectrophotometer (MD I3X). This measurement was repeated each day until day 5 , and growth curves were drawn. Each experiment was repeated three times, and the average values were taken. The cell doubling cycle was calculated using the following equation: $\mathrm{T}=\operatorname{tx} \lg 2 / \lg \left(\mathrm{OD}_{\mathrm{t}}-\mathrm{OD}_{0}\right)$, where $\mathrm{T}$ is the population doubling time, $t$ is the time of continuous culture, $\mathrm{OD}_{\mathrm{t}}$ is the final absorption of cells, and $\mathrm{OD}_{0}$ is the initial absorption of cells.

Evaluation of cell inhibition by MTT assay. The MTT cell viability/cytotoxicity assay kit (cat. no. C0009, Beyotime Institute of Biotechnology) was used for this assay. PC-3 and PC-3/DTX cells were seeded onto 96-well plates at a density of $1 \times 10^{4}$ cells/well at $37^{\circ} \mathrm{C}$ in a $95 \%$ humidified atmosphere with $5 \% \mathrm{CO}_{2}$ for $24 \mathrm{~h}$. Following washing with PBS, the following concentrations of docetaxel: $0.781,1.562,3.125,6.250,12.500$, $25.000,50.000$ and $100.000 \mathrm{nM}$, were added to the cells, which were then incubated for $72 \mathrm{~h}$. After introducing $10 \mu \mathrm{l}$ MTT solution for $4 \mathrm{~h}$, formazan was dissolved using formazan solvent in the kit and $100 \mu \mathrm{l}$ formazan was added to each well. The absorption at $570 \mathrm{~nm}$ was measured using a microplate spectrophotometer (MD I3X). Each experiment was repeated three times, and the average values were used for analyses. Resistance indices (RIs) were calculated as the ratio of the $50 \%$ inhibitory concentration $\left(\mathrm{IC}_{50}\right)$ values of PC-3/DTX to that of PC-3 cells.

Cell-cycle detection by flow cytometric analysis. For cell cycle analysis, the cells were processed using the cell cycle and apoptosis analysis kit (cat. no. C1052, Beyotime Institute of Biotechnology). PC-3 and PC-3/DTX cells were harvested and resuspended at a density $2 \times 10^{5}$ cells $/ \mathrm{ml}$ in $500 \mu \mathrm{l}$ binding buffer. According to the instruction of the kit, $5 \mu \mathrm{l}$ propidium iodide (PI) and RNase were added to the samples and incubated at $4^{\circ} \mathrm{C}$ for $30 \mathrm{~min}$. Next, the cells were resuspended in $500 \mu \mathrm{l}$ PBS and analyzed using a flow cytometer (BD-FACS-Calibur; BD Biosciences). The fluorescence of PI was monitored at $488 \mathrm{~nm}$. Fluorescence intensity was quantified by flow cytometry analysis. Each plot represented 20,000 viable cells, and non-viable cells were excluded from flow cytometric analysis by appropriate gating. All data analyses were performed using FCS express V3.0 (BD Biosciences).

Western blot analysis. Cells were collected in RIPA buffer (containing 0.2\% Triton X-100, $5 \mathrm{mmol} / 1$ EDTA, $1 \mathrm{mmol} / 1$ PMSF, $10 \mathrm{mg} / \mathrm{ml}$ leupeptin, $10 \mathrm{mg} / \mathrm{ml}$ aprotinin, added with $100 \mathrm{mmol} / 1 \mathrm{NaF}$, and $2 \mathrm{mmol} / \mathrm{Na}_{3} \mathrm{VO}_{4}$ ) and lysed for $30 \mathrm{~min}$ on ice.Protein concentration was assayed using the Bio-Rad protein kit (Beyotime Institute of Biotechnology, Haimen, China), and equal amounts of $10 \mu 1$ sample were loaded per well on a sodium dodecyl sulfate-polyacrylamide gel. Subsequently, proteins were transferred onto $0.45 \mu \mathrm{m}$ pore sized positively-charged nylon polyvinylidene difluoride membranes (EMD Millipore, Billerica, MA, USA) and blocked with blotto (5\% dry milk in PBS with $0.1 \%$ Tween-20) at room temperature for $1 \mathrm{~h}$. The cells were incubated with the following primary 
PC-3
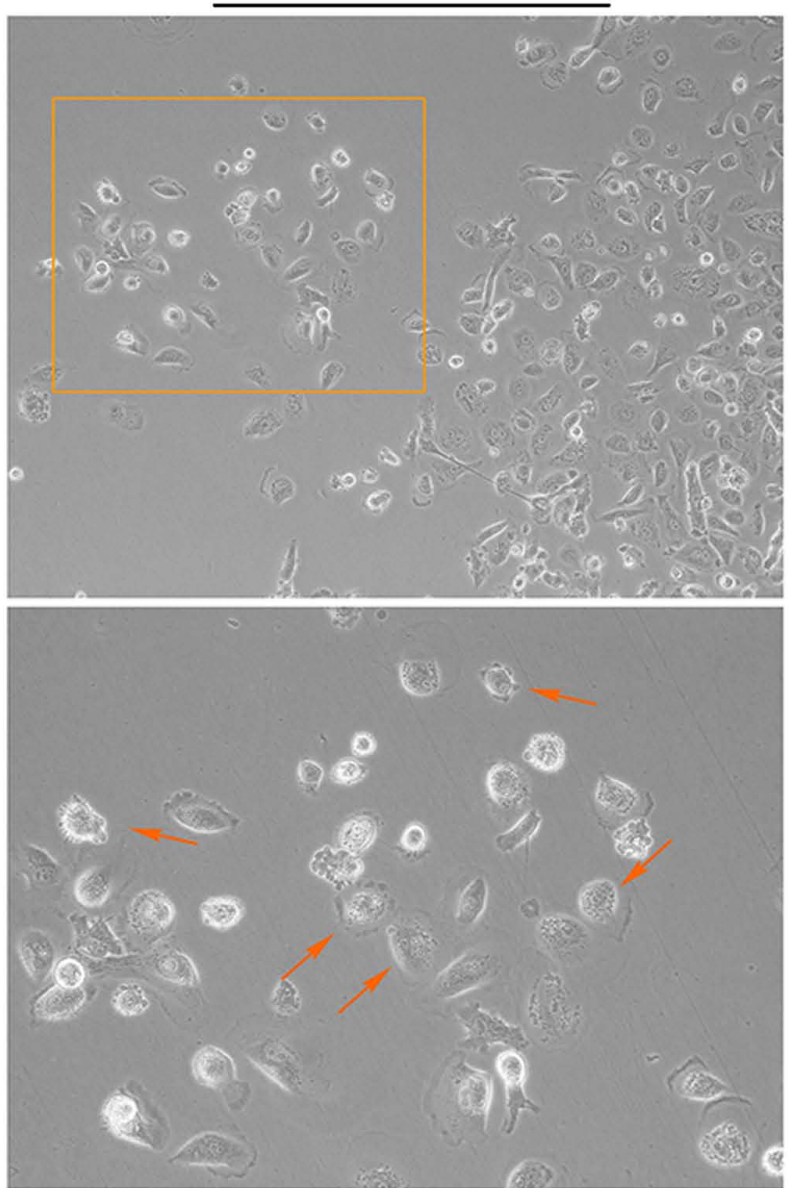

PC-3 / DTX
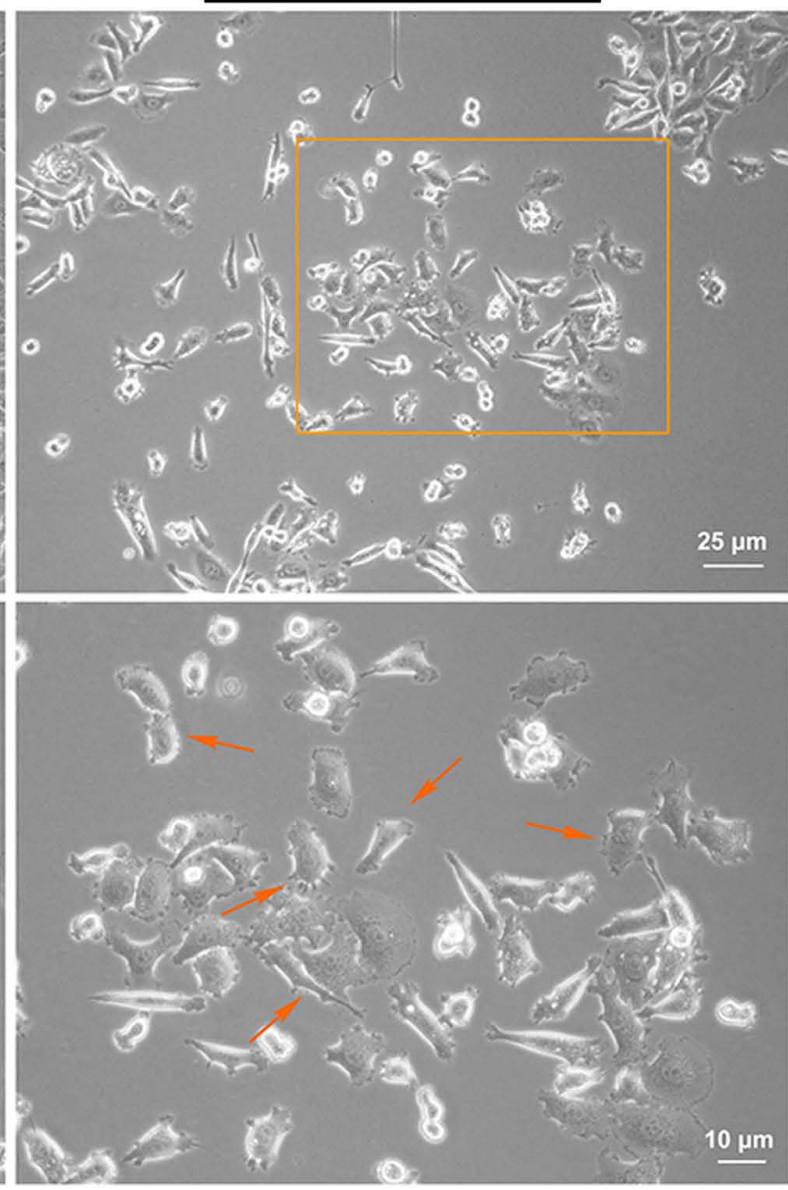

Figure 1. Establishment of the docetaxel-resistant PC-3/DTX cell line. The phenotype of PC-3 and PC-3/DTX cells were captured using an inverted microscope. The bottom panel is a magnification of indicated section in the upper panel. The arrow indicates the typical morphology of PC-3 and PC-3/DTX cells. All images represent three independent experiments $(\mathrm{n}=3)$. Scale bar $=10 \mu \mathrm{m}$. PC-3/DTX, docetaxel-resistance PC-3 cells.

antibodies: Anti-Rictor [1:1,000; Cell Signaling Technology (CST), Inc.; cat. no. 2114], anti-Raptor (1:1,000; CST; cat. no. 2280T), anti-AKT (1:1,000; ProteinTech Group, Inc.; cat. no. 10176-2-AP), anti-pAKT (S473; 1:1,000; CST; cat.no.9271T), anti-p70 S6 kinase 1 (1:1,000; CST; cat. no.2708), anti-p70S6k (T389; 1:1,000; CST; cat. no. 9234T), anti-4EBP1 (1:1,000; CST; cat. no. 9644T), anti-4EBP1-S65 (1:1,000; CST; cat. no. 9451T) and anti-GAPDH (1:1,000, CST; cat. no. 5174T) overnight at $4^{\circ} \mathrm{C}$, followed by washing three times with PBST $(0.1 \%$ Tween-20). They were then incubated with horseradish peroxidase-conjugated goat anti-rabbit $\operatorname{IgG}(\mathrm{H}+\mathrm{L})$ secondary antibodies (Beyotime Institute of Biotechnology; 1:1,000; cat. no. A0208) in TBS-T for $1 \mathrm{~h}$ at room temperature. The blots were detected using an enhanced chemiluminescent substrate (Beyotime Institute of Biotechnology).

Statistical analysis. All data are presented as the mean \pm standard deviation for the indicated number of separate experiments. Three independent experiments were performed for each study. Comparisons of differences in the quantitative data among groups were performed using an unpaired t-test. $\mathrm{P}<0.05$ was considered to indicate a statistically significant difference. SPSS 19 software (IBM Corp.) was used for statistical analyses.

\section{Results}

Establishment of the docetaxel-resistant PC-3/DTX cell line. PC-3 cells were exposed to increasing concentrations of docetaxel intermittently for 12 months to establish a stable docetaxel-resistant cell line, PC-3/DTX. As shown in Fig. 1, the cell phenotype was captured using an inverted microscope (magnifications, $\mathrm{x} 10$ and $\mathrm{x} 20$ ). Compared to the PC-3 cells, the gap junction was increased and more irregular cell margins were observed in PC-3/DTX cells. The cell inhibition analysis demonstrated that the $\mathrm{IC}_{50}$ values for PC-3 and PC-3/DTX cells were 4.75 \pm 0.05 and $52.00 \pm 0.04 \mathrm{nM}$, respectively (Fig. 2). The resistance index of PC-3/DTX cells was 10.9 times that of PC-3 cells, suggesting that PC-3/DTX cells exhibited a high resistance to docetaxel.

Growth curves and doubling time $\left(T_{d}\right)$ of $P C-3$ and $P C-3 / D T X$ cells. The cell growth curves are presented in Fig. 3. No significant differences were observed between the growth curves of PC-3 and PC-3/DTX cells in 2 days. After 2 days, PC-3/DTX cells grew more slowly than PC-3 cells, as can be observed by the decrease in the growth curve. The $T_{d}$ of PC-3 and PC-3/DTX cells was 25.34 \pm 0.02 and 28.87 $\pm 0.75 \mathrm{~h}$, respectively. 

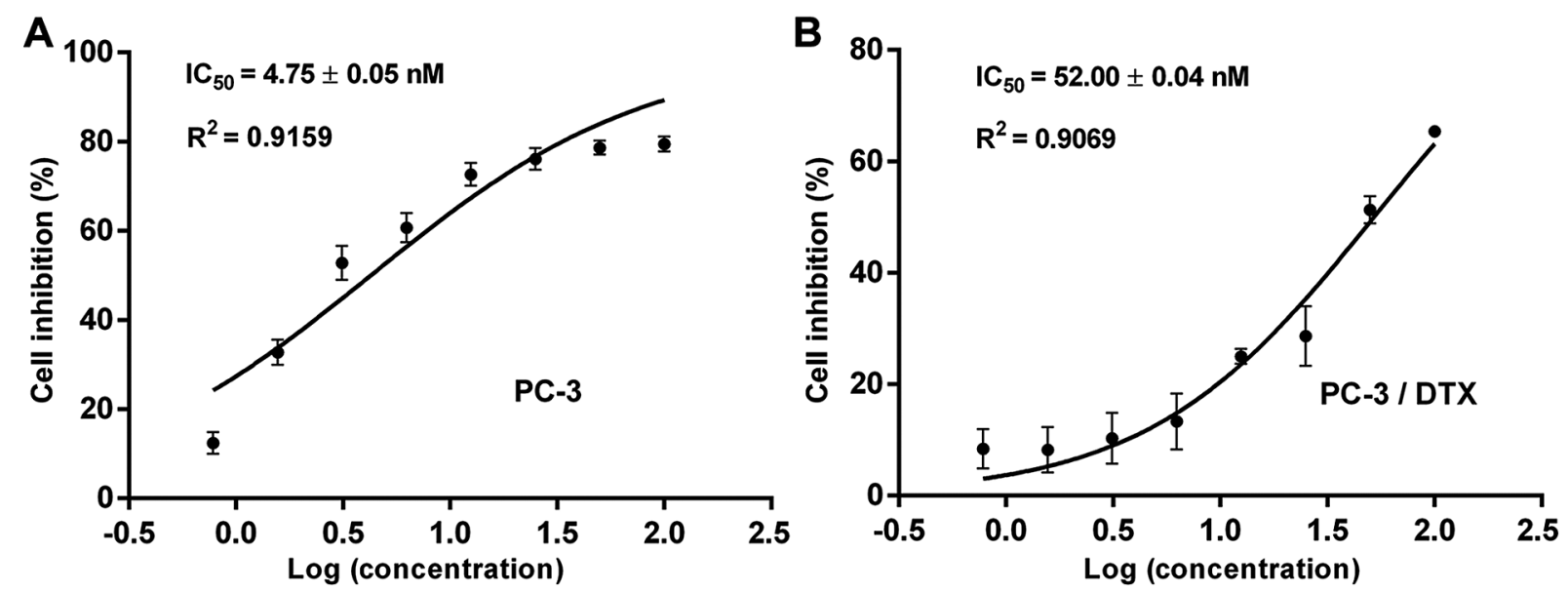

Figure 2. The evaluation of cell inhibition in PC-3 and PC-3/DTX cells treated with docetaxel using MTT assays. (A) PC-3 cells were treated with increasing concentrations of docetaxel over $72 \mathrm{~h}$. (B) Sensitivity of PC-3/DTX with the paralleled treatment. The absorption at $570 \mathrm{~nm}$ was measured by SpectraMax i3x (MD). PC-3/DTX, docetaxel-resistance PC-3 cells; $\mathrm{IC}_{50}, 50 \%$ maximum inhibitory concentration.

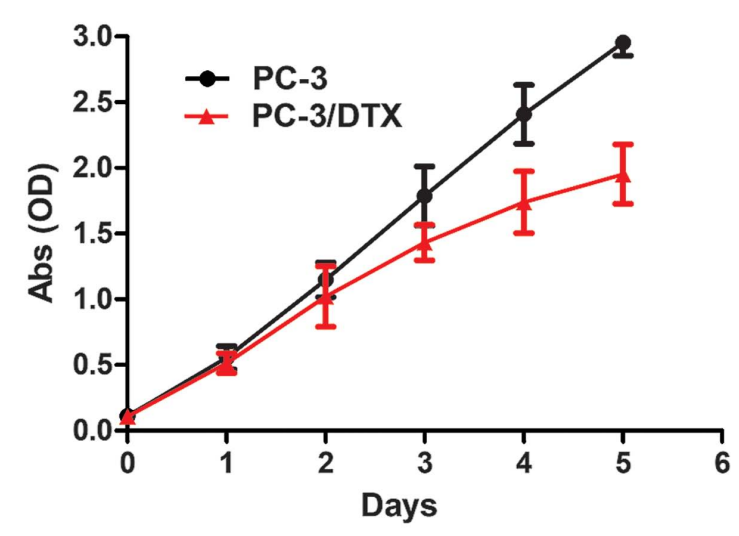

Figure 3. The growth curves of PC-3 and PC-3/DTX cells. The cell growth curves were plotted with culture time on the $\mathrm{x}$-axis and the average Abs per day on the $\mathrm{y}$-axis. Data are expressed as the mean \pm standard deviation. $\mathrm{n}=3$. PC-3/DTX, docetaxel-resistance PC-3 cells, Abs, absorbance.

Cell-cycle analysis of $P C-3$ and $P C-3 / D T X$ cells assessed by flow cytometry. The cell cycle of PC-3 and PC-3/DTX cells was assessed by flow cytometry. The results showed significant changes in the $G_{0} / G_{1}$ phase and $S$ phase between PC-3 and PC-3/DTX cells (Fig. 4). The distributions of PC-3 and PC-3/DTX cells in the $\mathrm{G}_{0} / \mathrm{G}_{1}$ phase were $48.09 \pm 2.20$ and $60.48 \pm 2.10 \%$ and those in $\mathrm{S}$ phase were $35.61 \pm 1.80$ and $20.99 \pm 0.38 \%$, respectively. Compared with PC-3 cells, the number of PC-3/DTX cells in the $\mathrm{G}_{0} / \mathrm{G}_{1}$ phase was $12.39 \%$ higher $(\mathrm{P}<0.05)$ and $14.62 \%$ lower in the $\mathrm{S}$ phase $(\mathrm{P}<0.01)$. There were no significant differences between the two cell lines with respect to the $\mathrm{G}_{2} / \mathrm{M}$ phase.

Protein changes in the mTORC2 signal pathway in PC-3/DTX cells. The expression of Rictor and p-AKT(S473), which are specific subunits or downstream substrates of mTORC2, were significantly upregulated in PC-3/DTX cells (Fig. 5A and B). By contrast, the expression of Raptor, p70S6K (T389) and 4EBP1-S65, which are specific subunits or downstream substrates of mTORC1, exhibited no notable changes (Fig. 5C and D).

\section{Discussion}

Chemotherapy is the main method of treatment for cancer. However, the occurrence of drug resistance is one of the main reasons for the poor effect of chemotherapy in patients with cancer. In patients with $\mathrm{mCRPC}$, docetaxel serves as the standard first-line chemotherapy following failure of ADT. Docetaxel is a microtubule stabilizer that may inhibit microtubule disassembly, thereby leading to G2/M cell-cycle arrest and several forms of cell death, including apoptosis and mitotic catastrophe (5). However, various mechanisms have been studied to interpret the existence of drug resistance that may be attributable for the unsatisfactory clinical outcomes in patients, for which the activation of compensatory pro-survival signaling pathways independent of the AR is one potential mechanism (5). Several preclinical studies have demonstrated that docetaxel may increase Akt phosphorylation (p-Akt) at S473, a direct downstream target of mTORC2, in prostate cancer cells (8). In line with this, compared with drug-naïve cells, prostate cancer cells that have gained resistance to docetaxel after an extremely long-term drug exposure exhibit greater expression of p-Akt (S473) (8). These findings indicated the possibility that the mTORC2 pathway, as indicated by increased p-Akt, may cause CRPC cells to become refractory to docetaxel, a putative mechanism that has not previously been investigated.

Few studies have focused on prostate cancer drug-resistant cell lines, which has impeded research on the mechanism of drug resistance in prostate cancer. The establishment of drug-resistant cell lines is important to study the biological characteristics, drug-resistant mechanism, and methods to overcome drug resistance.

In the present study, a docetaxel-resistant prostate cancer cell line was established in vitro as a model to investigate chemotherapy resistance by intermittently exposing prostate cancer parental cells to a high concentration of docetaxel with time-stepwise increments. The drug concentrations were increased to select cancer cell with drug resistance; this method may accurately simulate the biological changes of tumor resistance. Compared with the parental PC-3 cells, PC-3/DTX cells 


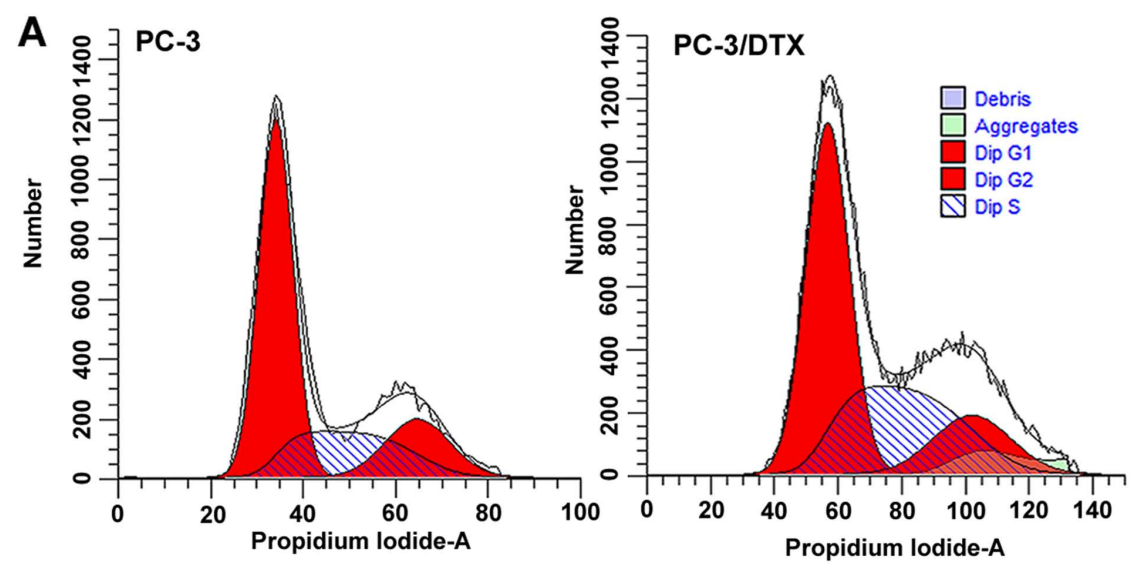

B

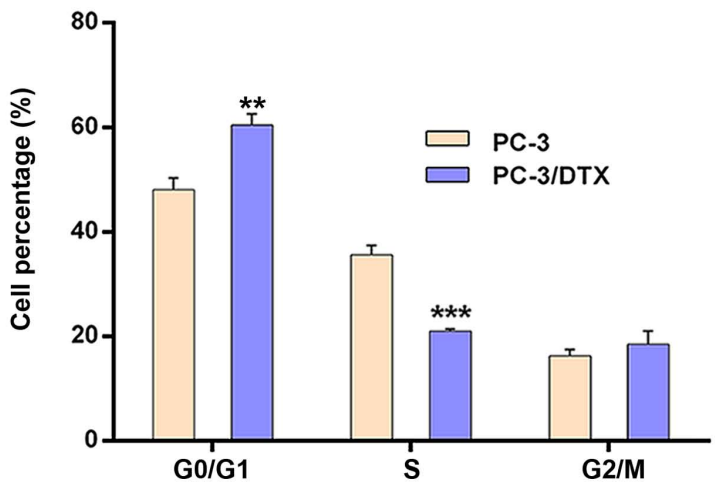

Figure 4. The cell cycle analysis of PC-3 and PC-3/DTX cells assessed by flow cytometry. (A) The cell cycle of PC-3 and PC-3/DTX cells. The fluorescence of PI was monitored at $488 \mathrm{~nm}$. (B) Quantification of fluorescence intensity by flow cytometry analysis. Each plot represented 20,000 viable cells (non-viable cells were excluded from flow cytometry analysis by appropriate gating). Data are expressed as the mean \pm standard deviation. $n=3 .{ }^{* *} \mathrm{P}<0.01,{ }^{* * * *} \mathrm{P}<0.001$ vs. control. PC-3/DTX, docetaxel-resistance PC-3 cells.

A
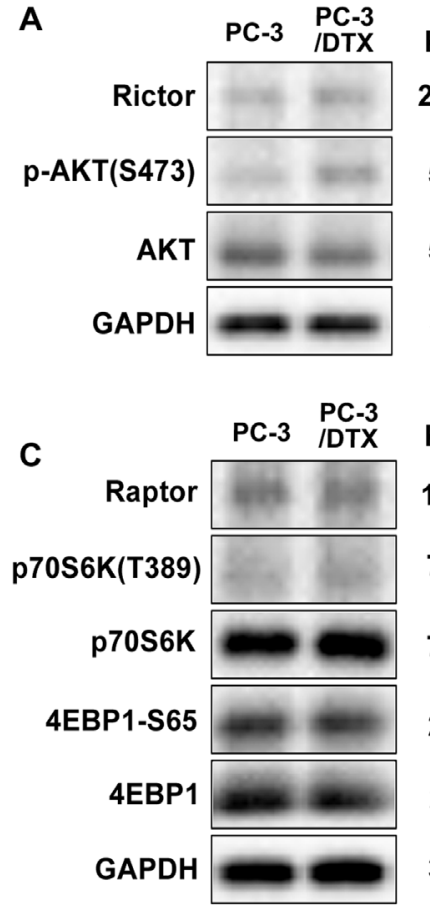

B

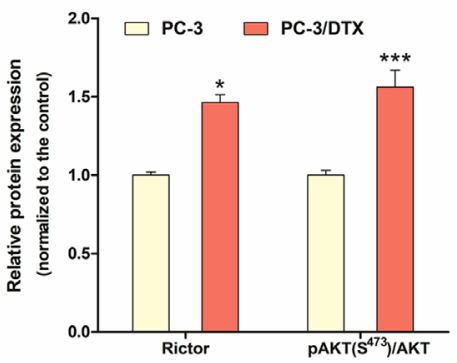

D

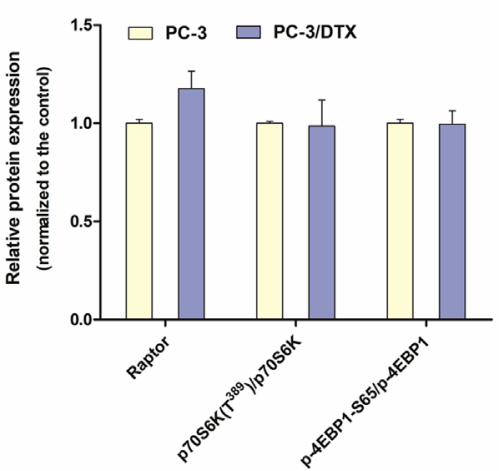

Figure 5. Western blot analysis of protein expression associated with the mTORC2 and mTORC1 signal pathway in the docetaxel-resistant PC-3 cells. (A) The protein expression of Rictor, p-Akt (S473) and Akt. (B) Quantification of protein expression levels of Rictor, p-Akt (S473) and Akt. (C) The protein expression of Raptor, p70 S6K1 (T389), p70 S6K1, 4E-BP1-S65 and 4E-BP1. (D) Quantification of the protein expression levels of Raptor, p70 S6K1 (T389), p70 S6K1, 4E-BP1-S65 and 4E-BP1. Data are presented as the mean \pm standard deviation of independent experiments performed in triplicate. ${ }^{*} \mathrm{P}<0.05,{ }^{* * *} \mathrm{P}<0.001$ vs. control. PC-3/DTX, docetaxel-resistance PC-3 cells; mTOR, mammalian target of rapamycin; Akt, protein kinase B; p-Akt, phosphorylated Akt; 4E-BP1, eukaryotic initiation factor 4E binding protein 1; p70 S6K1, p70 S6 kinase 1. 
showed 10.9-times more resistance to docetaxel, indicating that PC-3/DTX cells exhibited significant drug resistance to docetaxel. In the present study, the growth of resistant cells and parental cells was found to be similar, and the $\mathrm{T}_{\mathrm{d}}$ of PC-3/DTX and PC-3 cells did not exhibit a significant difference (28.87 vs. $25.34 \mathrm{~h}$ ). The difference in the cell proliferation rate was marked with 3-5 days, meaning that PC-3/DTX cells showed a delay in the initiation of the logarithmic growth. More PC-3/DTX cells were in the $G_{0} / G_{1}$ phase and fewer cells were in the $\mathrm{S}$ phase. A comparison of the biological characteristics of the PC-3 and PC-3/DTX cells revealed that the growth of the drug-resistant cells was relatively slower, and the cell cycle of PC-3/DTX cells was altered.

mTOR is an oncoprotein that is generally dysregulated in human cancer. In prostate cancer, the mTOR pathway is frequently hyperactivated primarily due to the loss of function of the upstream tumor suppressor, phosphatase and tensin homolog (PTEN), which occurs in $\sim 40 \%$ of primary tumors and $\sim 70 \%$ of metastatic lesions $(6,7)$. Consequently, aberrant mTOR expression has been revealed to be associated with disease progression and poor clinical outcomes in prostate cancer (9). Notably, PTEN loss is also found in up to $80 \%$ of mCRPC patients (10), suggesting a high prevalence. This clinical observation is supported by the preclinical findings demonstrating that loss of PTEN is a driving force for developing castration resistance in mice (11). In line with this, cumulating evidence strongly indicates that Akt/mTOR signaling, which is PTEN downstream, is activated in advanced prostate cancer, particularly in CRPC (9).

It has been reported that the mTOR pathway serves a crucial role in cancer; it regulates cell growth and cell survival. Two distinct protein complexes, mTOR complex 1 (mTORC1) and mTOR complex 2 (mTORC2), are involved in the regulation of cell function. Therefore, the present study evaluated the protein expression of the mTOR signaling pathway in docetaxel-resistant PC-3/DTX cells. Functionally, mTOR serves a pleiotropic role in the regulation of malignant phenotypes, including proliferation, metabolism, angiogenesis and drug resistance. At the molecular level, mTOR functions as two distinct complexes, mTORC1 and 2, downstream of PI3K signaling. Raptor and Rictor are two key proteins composing mTORC1 and 2, respectively. mTORC1 phosphorylates two downstream targets, p70 S6K1 and eukaryotic initiation factor 4E binding protein 1 (4E-BP1), regulating protein translation, cell size, cell proliferation, and survival. By contrast, mTORC2 may directly phosphorylate AGC family proteins, including Akt and PKC $\alpha$, and regulates cell survival, cytoskeleton rearrangement, and cell migration $(6,12)$. Preclinical studies have demonstrated that mTORC1 promotes tumor growth, invasion, and angiogenesis in prostate cancer models (13-16). Notably, mTORC2 is critical for the prostate cancer tumorigenesis driven by PTEN loss, but is dispensable for normal prostatic epithelial functions (17), supporting the selective role of mTORC2 in prostate cancer. The results of the present study demonstrated that PC-3/DTX cells exhibited stronger mTORC2 activity and downstream signaling pathways. This new finding suggested that the mTORC2 signaling pathway may serve an important role in the regulation of the docetaxel resistance of PC-3 cells. In future studies, the impact of mTORC 2 signaling on the acquired docetaxel resistance of CRPC cells and the potential of agents targeting mTORC2 in reversing docetaxel resistance in vitro should be investigated.

In conclusion, a stable docetaxel-resistant PC-3 cell line was established. This cell line may serve as a useful cell model to further study the molecular mechanisms of prostate cancer drug resistance and may lead to the establishment of novel therapeutic strategies for prostate cancer.

\section{Acknowledgements}

The authors would like to thank Ms Meijia Wu from the Research Center for Clinical Pharmacy, Zhejiang Provincial Key Laboratory for Drug Evaluation and Clinical Research, State Key Laboratory for Diagnosis and Treatment of Infectious Disease, The First Affiliated Hospital, Zhejiang University School of Medicine (Hangzhou, China) for providing technical assistance.

\section{Funding}

The present study was supported by grants from the National Natural Science Foundation of China (grant no. 81702862).

\section{Availability of data and materials}

The datasets used and/or analyzed during the present study are available from the corresponding author upon reasonable request.

\section{Authors' contributions}

JL was the principal investigator in the study and was responsible for the literature search, study design, data interpretation, and manuscript writing and revision. $\mathrm{YH}$ and DL were the main executors of the study, contributed toward carrying out the study, data analysis, and manuscript writing. YZ and XL performed cell culture. YD participated in the design of the present study and manuscript revision. DZ, LW and QZ participated in the design of the present study and data interpretation. All authors read and approved the final manuscript, and agreed to be accountable for all aspects of the research in ensuring that the accuracy or integrity of any part of the study were appropriately investigated and resolved.

\section{Ethics approval and consent to participate}

Not applicable.

\section{Patient consent for publication}

Not applicable.

\section{Competing interests}

The authors declare that they have no competing interests.

\section{References}

1. Bray F, Ferlay J, Soerjomataram I, Siegel RL, Torre LA and Jemal A: Global cancer statistics 2018: GLOBOCAN estimates of incidence and mortality worldwide for 36 cancers in 185 countries. CA Cancer J Clin 68: 394-424, 2018. 
2. Siegel RL, Miller KD and Jemal A: Cancer statistics, 2018. CA Cancer J Clin 68: 7-30, 2018

3. Pagliarulo V: Androgen deprivation therapy for prostate cancer. Adv Exp Med Biol 1096: 1-30, 2018.

4. Pienta KJ and Bradley D: Mechanisms underlying the development of androgen-independent prostate cancer. Clin Cancer Res 12: 1665-1671, 2006.

5. Seruga B, Ocana A and Tannock IF: Drug resistance in metastatic castration-resistant prostate cancer. Nat Rev Clin Oncol 8: 12-23, 2011.

6. Guertin DA and Sabatini DM: Defining the role of mTOR in cancer. Cancer Cell 12: 9-22, 2007.

7. Taylor BS, Schultz N, Hieronymus H, Gopalan A, Xiao Y, Carver BS, Arora VK, Kaushik P, Cerami E, Reva B, et al: Integrative genomic profiling of human prostate cancer. Cancer Cell 18: 11-22, 2010.

8. Kosaka T, Miyajima A, Shirotake S, Suzuki E, Kikuchi E and Oya M: Long-term androgen ablation and docetaxel up-regulate phosphorylated Akt in castration resistant prostate cancer. J Urol 185: 2376-2381, 2011.

9. Morgan TM, Koreckij TD and Corey E: Targeted therapy for advanced prostate cancer: Inhibition of the PI3K/Akt/mTOR pathway. Curr Cancer Drug Targets 9: 237-249, 2009.

10. Lunardi A, Ala U, Epping MT, Salmena L, Clohessy JG, Webster KA, Wang G, Mazzucchelli R, Bianconi M, Stack EC, et al: A co-clinical approach identifies mechanisms andpotential therapiesfor androgen deprivation resistance in prostate cancer. Nat Genet 45: 747-755, 2013.

11. Mulholland DJ, Tran LM, Li Y, Cai H, Morim A, Wang S, Plaisier S, Garraway IP, Huang J, Graeber TG and Wu H: Cell autonomous role of PTEN in regulating castration-resistant prostate cancer growth. Cancer Cell 19: 792-804, 2011.
12. Zoncu R, Efeyan A and Sabatini DM: mTOR: From growth signal integration to cancer, diabetes and ageing. Nat Rev Mol Cell Biol 12: 21-35, 2011.

13. Nardella C, Chen Z, Salmena L, Carracedo A, Alimonti A, Egia A, Carver B, Gerald W, Cordon-Cardo C and Pandolfi PP: Aberrant Rheb-mediated mTORC1 activation and Pten haploinsufficiency are cooperative oncogenic events. Genes Dev 22: 2172-2177, 2008

14. Clohessy JG, Reschke M and Pandolfi PP: Found in translation of mTOR signaling. Cell Res 22: 1315-1318, 2012.

15. Thoreen CC, Chantranupong L, Keys HR, Wang T, Gray NS and Sabatini DM: Aunifying model for mTORC1-mediated regulation of mRNA translation. Nature 485: 109-116, 2012.

16. Hsieh AC, Liu Y, Edlind MP, Ingolia NT, Janes MR, Sher A, Shi EY, Stumpf CR, Christensen C, Bonham MJ, et al: The translationallandscape of mTOR signalling steers cancer initiation and metastasis. Nature 485: 55-64, 2012.

17. Guertin DA, Stevens DM, Saitoh M, Kinkel S, Crosby K, Sheen JH, Mullholland DJ, Magnuson MA, Wu $\mathrm{H}$ and Sabatini DM: mTOR complex 2 is required for the development ofprostate cancer induced by Pten loss in mice. Cancer Cell 15: 148-159, 2009.

(†) $\ominus$ This work is licensed under a Creative Commons Attribution-NonCommercial-NoDerivatives 4.0 International (CC BY-NC-ND 4.0) License. 